\title{
Research on the Screening of Antifungal Lactic Acid Bacteria and Its Characteristics
}

\author{
Xudong Zhang ${ }^{1}$ \\ ${ }^{1}$ College of Oceanology, Harbin Institute of Technology (Weihai), Weihai, Shandong, 264209
}

KEYWORDS: Antifungal Lactic; Bacteria Screening; Characteristics Research

\begin{abstract}
Natural preservative and biological corrosion has become a modern food science and biological sciences frontier and hot, with a screening of natural resources has become a new trend antibacterial activity biotechnology, food research. Lactic acid bacteria used in food and feed has a long history, it can reduce the $\mathrm{pH}$ of food and produce antimicrobial metabolites. In recent years, many studies have found that lactic acid bacteria and yeast fungi has some antibacterial function, its application to food has important practical value. In this thesis, using agar diffusion method Northeast pickles and traditional dairy products isolated 60 lactic acid bacteria antifungal activity screening, screened lactic acid bacteria have a good antifungal effect; secondly, the lactic acid bacteria fermentation characteristics and antibacterial conditions were studied; third, antibacterial substances preliminary separation and purification; subsequently, the strain AST18 as an auxiliary agent is added to ferment yogurt production, and study its antifungal effects of physical and chemical indicators and yogurt organoleptic indicators.
\end{abstract}

\section{Introduction}

It is reported that each year about 25 percent of the world's grain and oil crops due to the fungal toxin contamination inedible. Fermented food has become increasingly severe fungal contamination, mainly for certain species of Penicillium and Aspergillus in contaminated food can be detected to penicillin, Penicillin, ochratoxin A and citrinin. Penicillium and Aspergillus is a large number of major food and feed spoilage bacteria, fusarium often appear in the grain, they will lead to accumulation of mycotoxins. Penicillium different in different foods cold storage appear, often P. Roqueforti and P. commune will lead to corruption of hard cheese. Nearly smooth Candida, Rhodotorula, Hansenula Kluyveromyces (s) Debaryomyces yeast yogurt and other fermented dairy products are the major spoilage bacteria. China's agricultural and fodder common current harmfulness of major mycotoxins aflatoxin, Fusarium alcohol, zearalenone, fumonisin and ochratoxin A and the like. Quality mycotoxins can lead to a variety of agricultural products and food nutrition material damage, mold failure deterioration, and the resulting product was reduced. Mycotoxins through the body of human and animal DNA, RNA, and protein synthesis inhibition of various enzymes, as well as the destruction of the cell structure and cause mycotoxin poisoning. Therefore, the study of mycotoxins on agricultural Harm and detection technology has been more and more people's attention. Mycotoxin contamination of agricultural products and processed foods in 2002, has been the World Health Organization as of foodborne illness a major source. 


\section{Separation of Antifungal Lactic Acid Bacteria and Its Identification}

Purified vacuum lyophilization inoculated on skim milk medium at $37{ }^{\circ} \mathrm{C}$ culture $24 \mathrm{~h}$, the activation of three generations. Coli was inoculated into MRS broth medium, was inoculated bacteria in GM17 broth, $37{ }^{\circ} \mathrm{C}$ cultured 48h. Broth through $4000 \mathrm{r} / \mathrm{min}$ centrifugation $10 \mathrm{~min}$, the supernatant was collected. The supernatant was filtered through a $0.22 \mu \mathrm{m}$ membrane, spare.

2.2.3 will be separated into the indicator bacteria Penicillium sp. In PDA (potato agar) slant medium $30{ }^{\circ} \mathrm{C}$ cultured $7 \mathrm{~d}$, until sporulation. Containing $0.05 \%(\mathrm{v} / \mathrm{v})$ Tween 80 in sterile water slant with sterile gauze filter, and using a hemacytometer the spore concentration is modulated $106 \mathrm{~mL}-1$.

Bilayer tablet antagonistic law: the lower medium is a solid MRS agar medium, medium tested bacteria in the lower dash, a length of about $2 \mathrm{~cm}, 37{ }^{\circ} \mathrm{C}$ cultured for $48 \mathrm{~h}$, pour $10 \mathrm{ml}$ upper PDA medium and $106 \mathrm{cfu} / \mathrm{ml}$ bacterial suspension was applied to the upper medium. $30{ }^{\circ} \mathrm{C}$ culture $48 \mathrm{~h}$, observe the inhibitory situation. Oxford Cup: mold spores in suspension in a coating on a solid PDA culture medium, Oxford cup gently placed on the plate, standing 5min take $200 \mu 1$ lactic acid bacteria culture fluid injection Oxford cup. $30{ }^{\circ} \mathrm{C}$ culture $48 \mathrm{~h}$, observe the inhibitory situation.

Phenyl lactic acid by the high performance liquid chromatography (Agilent 1200, USA) was measured. The column was Agilent Zorbax Eclipse-C18 column (4.5mm* 150mm, $5 \mu \mathrm{m})$. Mobile phase A was $0.05 \%$ trifluoroacetic acid in methanol, mobile phase $\mathrm{B}$ was $0.05 \%$ aqueous trifluoroacetic acid. The flow rate was $1 \mathrm{~mL} / \mathrm{min}, \mathrm{A} / \mathrm{B}$ ratio at 0,20,23,25min were 0: 90,100: 0,100: 0,10: 90. Benzene acid detection wavelength was $210 \mathrm{~nm}$, injection volume of $10 \mu \mathrm{L}$.

Benzene standard products lactic acid concentrations were adjusted to $10 \mu \mathrm{g} / \mathrm{ml}, 25 \mu \mathrm{g} / \mathrm{ml}, 50$ $\mu \mathrm{g} / \mathrm{ml}$ and $100 \mu \mathrm{g} / \mathrm{ml}$, the concentration of abscissa, the peak area of the vertical axis do benzene lactate concentration standard curve. Broth $\mathrm{pH}$ value measurement antifungal effect seven lactic acid bacteria, lactic acid and acetic acid were used sterilized MRS broth adjusted to the same $\mathrm{pH}$, inhibition was measured diameter.

The skim milk is stored in the connected strains MRS broth medium, cultured 37 [deg.] C $18 \mathrm{~h}$, streak-cultured in MRS agar plates and allowed to grow a single colony.

On MRS agar plates were picked in $10 \mu \mathrm{L}$ of bacteria after centrifugation, the supernatant was used as a template denaturation sterilized water. Reaction conditions: $99{ }^{\circ} \mathrm{C}, 10 \mathrm{~min}$.

By Beijing Technology Co., Ltd. Tiangen TIANnamp Bacteria bacterial genome DNA extraction kit to extract this experiment strain genomic DNA, PCR amplification primers Shanghai Bao Biotechnology Co., Ltd. provided the primer sequence is as follows:

Primers: 16S.S (5_-GGTGTAGCGGGTGAAATGCGAA-3_) 16S.R (5_-CAGCCTACAATCCGAGCTGAG -3_) using TaKaRa 16s rDNABacterial Identification PCR Kit (Code No.D310), was PCR amplified fragment.

Preparation of $1.0 \%$ agarose gel, the amplification reaction is complete, the product was taken 5 $\mu \mathrm{L}$ PCR $1 \mu \mathrm{L}$, Loading buffer and mixed, subjected to electrophoresis voltage $5 \mathrm{~V} / \mathrm{cm}$ in the wells point agarose gel. After completion of the electrophoresis, the ethidium bromide stains it for 20-30 minutes. If the PCR is successful, the UV light can be seen approximately $1200 \mathrm{bp}$ bands. With Takara Bio's recycling kit (TaKaRa Code: DV805A) recovering purified PCR products.

In the above described sequence of DNA sequencing primer. Bacterial 16s rDNA sequencing results are applied to the sequence BLAST program with the US National Center for Biotechnology Information database it reported similarity comparison analysis. 


\section{Results and analysis}

In this study, isolated 18 Gram-positive from the fermentation of kimchi northeast, catalase negative, glucose acid-positive strains. Stored in our laboratory isolated from fermented dairy products to the lactic acid bacteria are 42 . Lactobacillus has 46, with short rod, pole, slender rod, was a chain or shape. Lactococcus 14, were round or oval, single, shape or chain to emerge. Lactic acid bacteria on MRS medium crossed $37{ }^{\circ} \mathrm{C}$ incubated for 2-3 days, colonies of Lactobacillus milky white or yellow, the central projection, the majority of bacilli jagged, rough surface dull. Some bacilli is translucent, neat edges and smooth surface. Size of $0.5-2 \mathrm{~mm}$. Cocci mostly white or transparent, neat edges, smooth surface, colony size is about $0.5-2 \mathrm{~mm}$. Figure 1 is a strain AST18 microscope after Gram stain morphology diagram 100x oil.

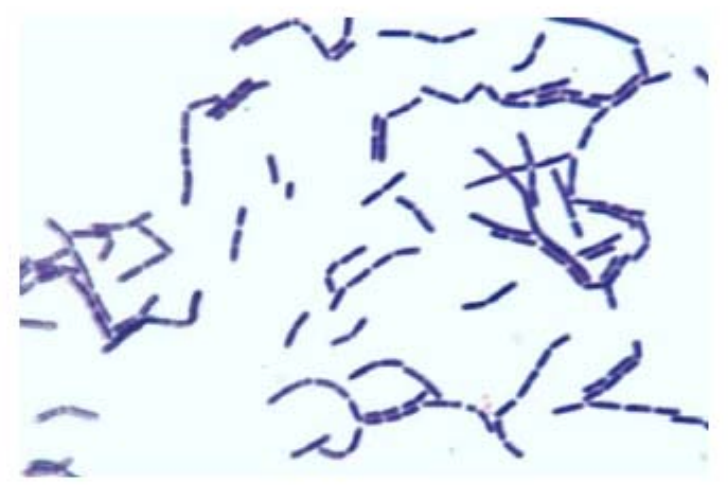

Fig.1 The Gram stain microscopy morphological chart of AST18 (100 times)

The lactic acid bacteria placed in $37{ }^{\circ} \mathrm{C}$, incubation supernatant after $48 \mathrm{~h}$ fermentation liquid antibacterial ability to measure the use of the Oxford Cup diffusion method. 9 Mucor lactic acid bacteria have a certain inhibitory effect, 10 strains of Penicillium better inhibition. Short dense mycelium of Penicillium, Mucor lactic acid bacteria fermentation broth is relatively more sensitive, easy observation of inhibition zone, subsequent test selected as an indicator of Penicillium mold. The screening of yeast strains corruption did not show inhibitory effect. 607 bacteria strains: PC12, AST18, A4, SY15, SY03, 3, 1014 better inhibition of Penicillium, and Mucor also shows some inhibitory effect of screening out as a strain further research.

Benzene standard products lactic acid concentrations were adjusted to $10 \mu \mathrm{g} / \mathrm{ml}, 25 \mu \mathrm{g} / \mathrm{ml}, 50$ $\mu \mathrm{g} / \mathrm{ml}$ and $100 \mu \mathrm{g} / \mathrm{ml}$, the concentration of abscissa, the peak area of the vertical axis do benzene lactate concentration standard curve. The results are shown in Figure 2.

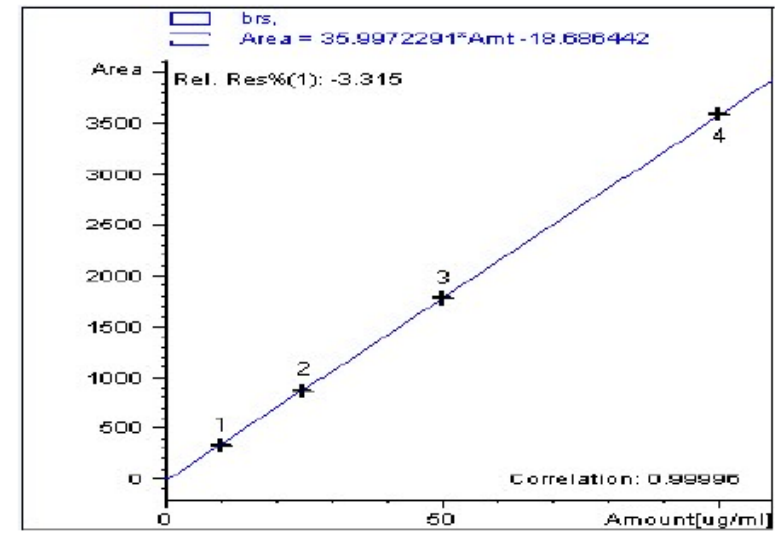

Fig.2 Standard curve of PLA 
Through SAS corr program terephthalic acid content and inhibition zone diameter correlation analysis and the results showed that the diameter of antibacterial lactic acid production with benzene linear correlation, polynomial fitting results quintic equation, we can see the correlation between the two variables obvious. 7 lactic acid fermentation broth $\mathrm{pH}$ value are between 3.78-3.92.

Previously prepared $1.0 \%$ agarose gel, the amplified after completion of the reaction, $5 \mu \mathrm{L}$ of the PCR product was taken was mixed with $1 \mu \mathrm{L} 6 \times$ Loadingbuffer, loaded onto an agarose gel electrophoresis spotted wells, voltage $5 \mathrm{~V} / \mathrm{cm}$. After electrophoresis, it stained with ethidium bromide for 20-30 minutes, observed under ultraviolet light. If the PCR is successful, you can see a band of approximately $1200 \mathrm{bp}$. Bao biotechnology company using the Gel Extraction Kit (TaKaRa Code: DV805A) recovering purified PCR amplification product.

\section{AST18 Fermentation Characteristics and Its Physicochemical Properties}

Lactic acid bacteria prime exhibit a high degree of hydrophobicity, high isoelectric point, cationic and other features, but the larger the difference between heat and acid stability, and with the improvement of purity, stability of the substance showing a decreasing trend. In addition, according to the relevant literature, some stability antibacterial substance with increasing the molecular weight is decreasing. But for low molecular weight polypeptides, it has good thermal stability. Such thermal stability may be due to its stable crosslinked structure, high hydrophobicity and high levels of glycine and other reasons. In addition, most of the lactic acid fermentation products will play a role in a neutral or acidic conditions as well as some inhibitory activity at alkaline conditions. Antibacterial substance is produced by the lactic acid bacteria of different species according to the different nature and belongs to different categories, physical and chemical properties of different types of antimicrobial substances, molecular size, antibacterial spectrum, etc. are very different.

Strain broth supernatant AST18 antibacterial substances were isolated and purified by ultrafiltration, preparative chromatography, ion chromatography and isolated by liquid organic acids were tested results showed that: (1) AST18 supernatant of the fermentation broth antibacterial substances It is a small molecule, a molecular weight of less than 3000Da. (2) in the fermentation broth, Part 2 (4.5-7.5min) and Section 4 (11.4-13.4min) appears relatively large zone of inhibition. (3) Part 2 of the preliminary analysis, it can be speculated that inhibitory effect was mainly due to the high concentration of organic acids (mainly lactic acid), due to its inhibitory effect or reduce the $\mathrm{pH}$ value plays an inhibitory effect. (4) Part 4 of GC-MS analysis, three kinds of small molecules separated organic compounds, including cyclic dipeptides ctclo- (Leu-Pro), 2,6- diphenyl-piperidine and pyrazine small molecular substances .

\section{Conclusion}

From the Chinese Traditional lactic acid bacteria fermented food - kimchi and laboratory, this article saved 60 lactic acid bacteria and screened for anti-fungal strains selected lactic acid bacteria have a good anti-fungal effect, and fermentation characteristics and the characteristics of its physical and chemical antimicrobial substances a preliminary study of antibacterial substances preliminary separation and purification, and the strain AST18 as an auxiliary agent is added to ferment yogurt, and its antifungal effects on the physical and chemical indicators and yogurt sensory index were studied

\section{Reference:}

[1] A Maroziene, C G Kruif Interaction of pectin and casein micelles [J]. Food Hydrocolloids, 
2000,14: 391-394.

[2] Axelsson, L. (1990). Lactobacillus reuteri, a member of the gut bacterial flora. PhD thesis, Swedish University of Agricultural Sciences, Uppsala, Sweden.

[3] Bennett JW, Papa KE The aflatoxigenic Aspergillus [J]. Adv Plant Patbol, 1988, 6: 265-279.

[4] Broberg, A., Jacobsson, K., Ström, K., Schnürer, J. Metabolite profiles of lactic acid bacteria ingrass silage [J] Applied and Environmental Microbiology, 2007, 73: 5547-5552.

[5] Brul, S., Coote, P. Preservative agents in foods. Mode of action and microbial resistance mechanisms [J]. International Journal of Food Microbiology, 1999, 50, 1-17. 